\title{
Interstitial lung disease associated with docetaxel in a patient treated for breast cancer - a case report
}

The authors declare no financial disclosure

\begin{abstract}
Docetaxel is a semisynthetic cytostatic drug that belongs to the family of taxoids. Docetaxel inhibits normal interphase and mitotic cellular function, causing cell death.

Docetaxel is indicated for the treatment of breast, lung and prostate cancers, head and neck cancer and gastric adenocarcinoma. Interstitial pneumonitis is an uncommon side effect of docetaxel. We report a case of docetaxel induced interstitial lung disease (ILD) in a patient with breast cancer.
\end{abstract}

Key words: interstitial lung disease, breast cancer, docetaxel

Pneumonol Alergol Pol 2015; 83: 378-382

\section{Introduction}

Docetaxel is a semisynthetic derivative of 10-deacetylbaccatin III obtained from the needles of yew species, such as the European yew (Taxus baccata). Along with paclitaxel it belongs to the taxoids, which have been introduced into clinical practice in the 90's of the past century. Docetaxel is commonly used in monotherapy and in combinations with doxorubicin and cyclophosphamide in the adjunctive treatment of breast cancer with metastases to lymph nodes, in the treatment of locally advanced breast cancer, advanced non-small-cell lung cancer (NSCLC), prostate cancer, stomach adenocarcinoma, head and neck cancer. It was approved for use in $\mathrm{Eu}$ ropean Union in 1995.

Docetaxel acts mainly by distorting microtubules. The spindle fibres formation is thus impaired and consequently mitosis and further proliferation of cells is inhibited. Taxoids also influence the microtubule associated proteins (MAPs) and the proteins of the mitotic cycle. They induce apoptosis, inhibit angiogenesis, cell mobility and synthesis of metalloproteinases. All these actions add up to their antineoplastic potential.

Neutropenia is the main toxicity of docetaxel. Also anaemia, nausea, vomiting, loss of hair, stomatitis, diarrhoea and malaise are frequently reported [1-3].

Infusion-related reactions (IRRs) often occur during taxoid therapy. IRRs are hypersensitivity reactions caused by degranulation of mast cells. They develop shortly after administration of the cytostatic drugs and manifest with cough, bronchospasm, dyspnoea, fever and falls in blood pressure [2]. The toxicity of docetaxel may be greater if infused in combination with other chemotherapeutic agents [4-7].

Interstitial lung disease (ILD) is a rare side effect of docetaxel therapy [1, 2, 8-12].

We present a patient with breast cancer treated with three cycles of docetaxel in combination with doxorubicin and cyclophosphamide who developed ILD mimicking hypersensitivity pneumonitis (HP).

Address for correspondence: Monika Pankowska-Supryn, XI Department of Lung Diseases, National Institute of Tuberculosis and Lung Diseases, ul. Płocka 26, 


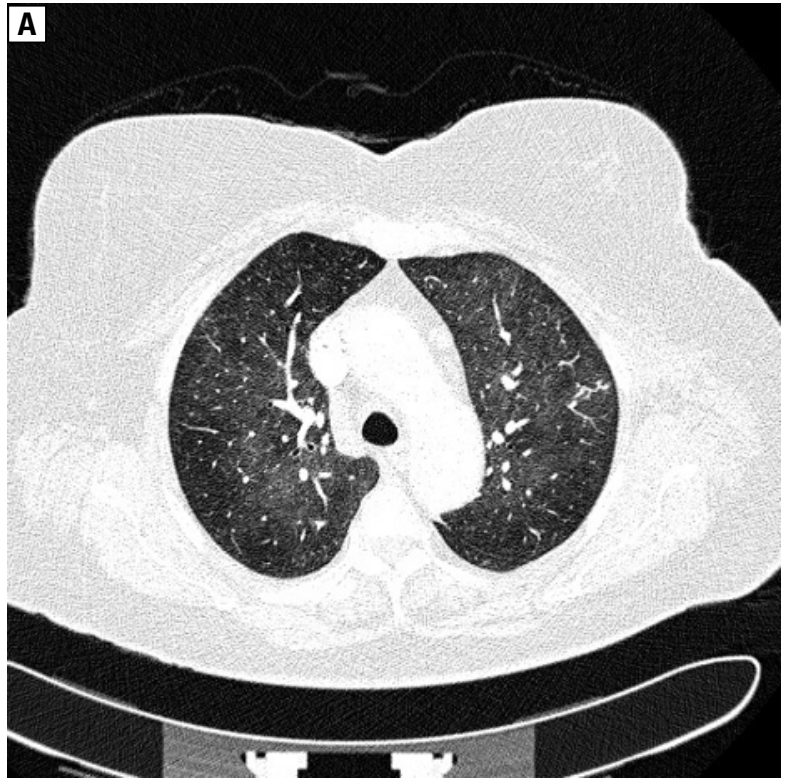

Figure 1. Computed tomography scan

\section{Case report}

A 61-year old, never-smoking, female with arterial hypertension and hyperthyroidism managed with thiamazole and propranolol, was admitted to the emergency unit of our Institution on $15^{\text {th }}$ April 2013 complaining of dyspnoea at rest that aggravated within past few days. Her past medical history revealed an episode of deep vein thrombosis of the left lower limb in 2010, which had been treated with a low molecular weight heparin (LMWH) for six months.

In January 2013 she underwent a sparing operation of left breast cancer with lymphadenectomy. Subsequently she has been scheduled for chemotherapy that comprised docetaxel, doxorubicin and cyclophosphamide. The third chemotherapy cycle was given on $20^{\text {th }}$ March 2013 and on the next day she developed fever of $38^{\circ} \mathrm{C}$ with dyspnoea and non-productive cough. She was initially treated as outpatient with amoxicillin and cefuroxime, with no effect.

On admission the patient was in a moderate general condition with tachycardia of $120 / \mathrm{min}$ and dyspnoea at rest. Auscultation revealed mild attenuation of vesicular murmur. There were no crackles. The patient complained of left-sided chest pain. There was no haemoptysis. She had been taking LMWH prophylactically at a dose of $40 \mathrm{mg}$ a day subcutaneously. Chest X-ray taken four days prior to admission showed interstitial opacities indicative of inflammation in the lower field of the left lung, unfortunately the picture was unavailable.

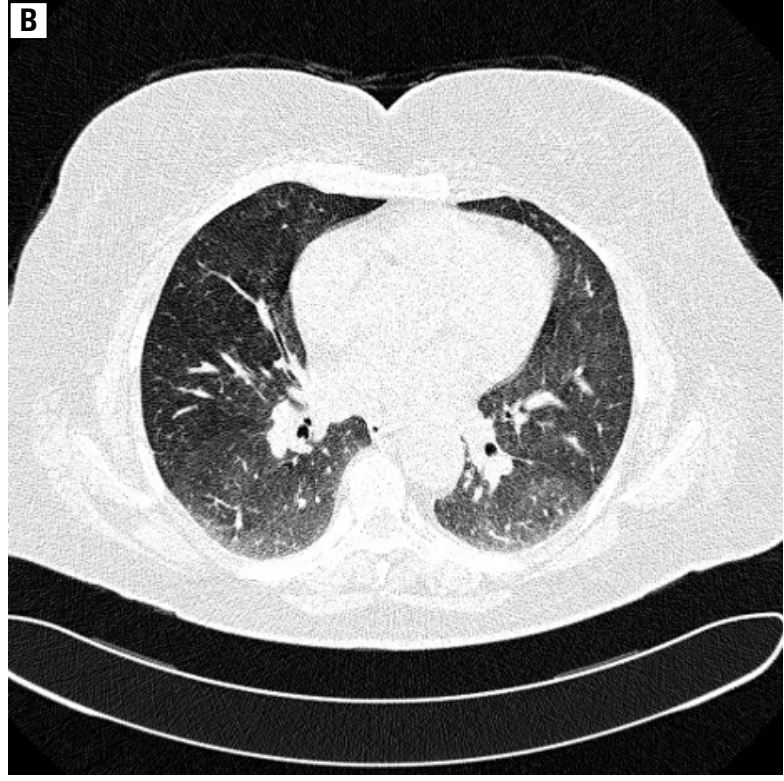

Analysis of capillary blood gases showed oxygen saturation of $95 \%, \mathrm{pO}_{2}-70.4 \mathrm{~mm} \mathrm{Hg}$, $\mathrm{pCO}_{2}-35.4 \mathrm{~mm} \mathrm{Hg}, \mathrm{pH}-7.47$, fibrin degradation products D-dimer - $1830 \mu \mathrm{g} / \mathrm{l}$ (reference range $68-494 \mu \mathrm{g} / \mathrm{l}$ ). The C-reactive protein (CRP) concentration was $25 \mathrm{mg} / \mathrm{l}$ (reference $<10 \mathrm{mg} / \mathrm{l}$ ). The blood count was normal.

Computed tomography (CT) of the chest with iodine contrast agent administration was performed. The dose of thiamazol was thus temporarily increased. No thrombi in the pulmonary arteries were found. However considerable variations in parenchymal density were notable. The overall picture was indicative of ILD with ground-glass opacities most prominent in the upper fields of both lungs. There was no air-trap upon expiration. Besides, small peribronchial opacifications were noted in the third segment of the left lung (Figs $1 \mathrm{~A}, \mathrm{~B})$. In the opinion of the radiologist the picture could have been associated with drug toxicity.

The patient recalled no contact with typical allergens. Also, precipitin reactions against antigens of thermophilic actinomycetes and farm bird faeces were negative. The ivestigation of ventilatory mechanics showed normal total lung capacity and vital capacity, and the airflow parameters remained within the reference range. The diffusing capacity for carbon monoxide (DLCO) was not evaluated due to poor compliance.

Due to poor clinical status of the patient, characteristic picture of CT findings, bronchoalvelar lavage (BAL) and transbronchial lung biopsy was considered unsafe and unnecessary. 


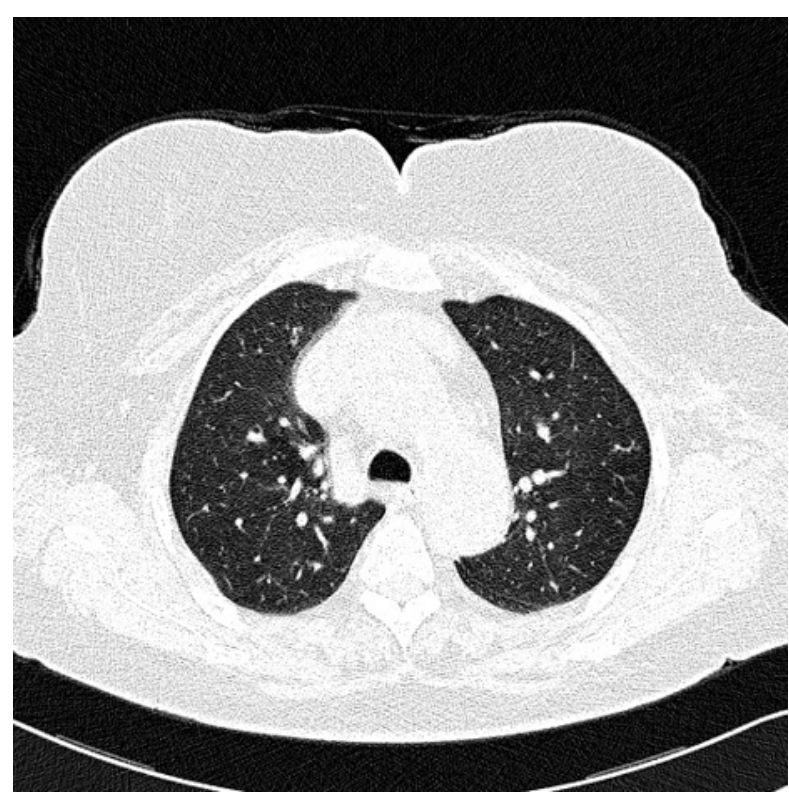

Figure 2. High resolution computed tomography

Taking into account the antineoplastic treatment that included pneumotoxic docetaxel and the radiological findings indicative of ILD we reached the decision to apply corticosteroids at an initial dosage of $0.5 \mathrm{mg} / \mathrm{kg}$ of body mass a day. Prednisone at a dose of $50 \mathrm{mg} /$ day was commenced along with ciprofloxacin due to the observed inflammatory infiltrates. The general condition of the patient improved.

The patient was followed at the end of May 2013 , one month after corticosteroid treatment initiation. She declared substantial improvement in general feeling and no dyspnoea. A high-resolution CT scan (HRCT) revealed absolute regression of infiltrates. There were no ground-glass opacities and no nodules, previously seen in the left third segment (Fig. 2). Spirometry was inconclusive due to poor compliance. The capillary blood gas analysis revealed oxygen saturation of $96 \%$, $\mathrm{pO}_{2}-86 \mathrm{~mm} \mathrm{Hg}, \mathrm{pCO}_{2}-33 \mathrm{~mm} \mathrm{Hg}$. During the 6-minutes walk test (6MWT) the patient walked the distance of $370 \mathrm{~m}$ with initial oxygen saturation of $98 \%$ and of $90 \%$ at the end of the test.

Due to the regression of radiological findings we decided to reduce the dosage of prednisone to $40 \mathrm{mg} /$ day.

The patient was admitted again in July 2013. At that time she remained in good general condition. The blood gas analysis was normal, the distance in $6 \mathrm{MWT}$ was $380 \mathrm{~m}$, during which oxygen saturation remained stable. The chest X-ray was normal.

We decided to further gradually reduce the dose of prednisone on outpatient basis without scheduled follow-up in our Institution.

\section{Discussion}

Adverse drug reactions are increasingly often seen in the respiratory system. They total to about $7 \%$ of all adverse drug reactions $[2,13]$.

Among the inadvertent reactions in respiratory system bronchospasm, bronchiolitis, pleural effusion, mediastinal lymphadenopathy, vascular reactions of pulmonary hypertension and thromboembolism, and hypersensitivity reactions are encountered. Interstitial lesions are a specific manifestation of reaction to antineoplastic drugs. These occur more often in the case of combined cytotoxic treatments, radiotherapy, long-term oxygen therapy, renal insufficiency, concomitant lung disease and advanced age [2, 13].

Among interstitial lung diseases: HP, usual interstitial pneumonia (UIP), organizing pneumonia (OP), desquamative interstitial pneumonia(DIP), diffuse alveolar damage (DAD), diffuse alveolar haemorrhage (DAH) and pulmonary vasculitis can be discerned $[3,4,13,14]$. According to the available literature the most common form of docetaxel-induced lung toxicity is HP $[2,7,11,12]$.

Docetaxel is a potent antitumor, yet toxic drug. It may cause pulmonary injury through multiple, currently poorly understood mechanisms. Various reactions have been described in the course of docetaxel treatment: anaphylactic hypersensitivity and infusion related reactions. The docetaxel-induced lung toxicity in the cases that have been reported usually occurred after the second to fourth course of chemotherapy, and was usually relieved with corticosteroid therapy. Therefore, the involvement of a cytotoxic T-cell-mediated mechanism is very likely $[1,2,4,8,15]$.

One of the earlier and thus better-explored toxoids - paclitaxel - induces acute bronchospasm and anaphylactic reactions in 30\% of patients not pre-treated with antihistamine drugs or corticosteroids. These reactions result probably from basophil injury and mast cells degranulation. Besides acute cough, fever and interstitial pulmonary infiltrates have been reported [2, 3, 13].

Cytotoxic drugs may distort the oxidation-reduction, immunological, metabolic, and neuroregulatory balances as well as reparative processes. They also impair the neutralization of free radicals by antioxidants, which results in pulmonary injury, inflammation and fibrosis. By indirect alterations in inflammatory processes they enhance the inflow of inflammatory cells and the destruction of pulmonary parenchyma [3]. 
Histopathological examination in cytostatic induced ILD often reveals atypical distorted type II pneumocytes with large hiperchromatic nuclei. In late hypersensitivity reactions infiltrates of atypical granulomas are common [3, 14].

Interstitial pneumonia may develop within days or weeks following administration of docetaxel. Initially the symptoms may be non-specific. There may be cough, fever, acute bronchiolitis, dyspnoea initially on exertion then at rest, or sudden dyspnoea as in non-cardiogenic pulmonary oedema [3, 15]. Respiratory failure may develop, being at times lethal [8].

Radiological examination shows variable levels of parenchyma involvement ranging from discreet, hardly discernible in conventional chest $\mathrm{X}$-rays, through ground-glass opacities, up to massive infiltrates $[3,13,14]$.

HRCT may reveal diffused nodo-reticular infiltrates, signs of alveolar flooding as in non-cardiogenic pulmonary oedema, alveolar haemorrhages or eosinophilic pneumonia. In acute HP radiological signs include localized or diffused infiltrates. In chronic states these infiltrates become nodular or reticulo-nodular. At that stage they tend to be more pronounced in the superior lobes. Typically seen in HRCT are the mosaic-like ground glass opacities [3, 13, 14].

According to Wang four patients with advanced NSCLC treated with docetaxel developed life-threatening HP requiring mechanical ventilation. The first patient developed symptoms five days following the first dose of docetaxel, and the remainder between the second and the sixth cycle of chemotherapy. The diagnosis was established based on the radiological findings after excluding connective tissue diseases, infection and metastases. The patients were treated with corticosteroids. Three out of four experienced partial remission, but eventually suffered from sustained interstitial disease and infective complications [11].

Grande et al. described a case of ILD induced by docetaxel following treatment of NSCLC. It resulted from type I and IV drug-related hypersensitivity reactions. In general, both clinical and radiological signs tend to be non-specific and the final diagnosis is pronounced after exclusion of other conditions. The disease is usually cured with corticosteroids, yet occasional progression to pulmonary fibrosis is possible [12].

Gurram et al. described a similar case to ours. A patient treated for advanced breast cancer developed HP following three cycles of docetaxel. It led to respiratory failure resulting in death, despite intensive corticosteroid therapy [8].

Ochoa reported interstitial pneumonia with fibrosis in a patient taking adjuvant chemotherapy comprising docetaxel and cyclophosphamide because of advanced breast cancer. Within two weeks following the third cycle of chemotherapy the patient developed rapidly progressing dyspnoea along with non-productive cough and mild hypoxemia. Chest CT scan showed subpleural lesions. Lung biopsy revealed subacute interstitial pneumonia. The patient improved quickly upon introduction of corticosteroids [7].

Docetaxel needs to be discontinued in all cases. The clinical, pathologic, and radiographic data supported pulmonary toxicity caused by a hypersensitivity reaction to docetaxel as the most likely etiology. The authors recommend, that any patient who develops a taxane- induced pulmonary toxic reaction, must not be rechallenged or treated with another agent of the same class [15].

\section{Conclusion}

Interstitial pneumonia is on occasion related to side effects of docetaxel treatment $[3,9,10]$. According to the available literature the most common form is HP $[7,8,11,12]$.

We presented a case of a patient who following three cycles of chemotherapy, given for breast cancer, developed symptoms of HP: fever, dyspnoea, dry cough and typical radiological signs.

The diagnosis was eventually established based on history, clinical signs and HRCT findings. We excluded pulmonary embolism and metastases to the respiratory system. Unfortunately it was not possible to fully evaluate ventilatory mechanics and DLCO due to poor compliance, which led to non-repeatable results.

Chemotherapy was terminated in our patient after three cycles out of planned six. The patient was then referred to radiotherapy. The use of corticosteroids led to full remission of interstitial lesions thus preventing respiratory failure and lung fibrosis, which in turn gave the patient an opportunity to pursue further antineoplastic treatment.

Oncologists should remember that patients have contraindication for continuation of chemiotherapy.

Familiarity with adverse effects of docetaxel, including possible reactions within the respiratory system is very important. The use of appropriate pre-treatment, comprising anti- 
histaminic drugs and corticosteroids may prevent complications. Appropriate recognition of simultaneously occurring symptoms, such as: impending dyspnoea, dry cough and fever in the context of possibly occurring ILD enables proper scheduling of diagnostics, early cytostatic withdrawal and appropriate corticosteroid administration.

\section{Conflict of interest}

The authors declare no conflict of interest.

\section{References:}

1. Taj A. Docetaxel induced hypersensitivity pneumonitis mimicking lymphangitic carcinomatosis in a patient with metastatic adenocarcinoma of the lung. Hematol Oncol Stem Cell Ther 2013; 3-4: 117-119. doi: 10.1016/j.hemonc.2013.08.005.

2. Talmadge EK, James RJ. Taxane-induced pulmonary toxicity. Up to Date 2013, www.uptodate.com; 1.02.2015.

3. Camus P. Interstitial lung disease from drugs, biologics, and radiation. In: King S. (ed.) Interstitial Lung Disease, Shelton 2011: 637-688.

4. Tamura M, Saraya T, Fujiwara M, Hiraoka S, Yokoyama T. High-resolution computed tomography findings for patients with drug-induced pulmonary toxicity with special reference to hypersensitivity pneumonitis-like patterns in gemcitabine -induced cases. Oncologist 2013; 18: 454-459. doi: 10.1634/ theoncologist.2012-0248.

5. Kim S, Tannock I, Sridhar S, Seki J, Bordeleau L. Chemotherapy-induced infiltrative pneumonitis cases in breast can- cer patients. J Oncol Pharm Pract 2012; 18: 311-315. doi: 10.1177/1078155211429384

6. Prat A, Martinez P, Serrano C, Montero MA, Andreu J, Cortes J. Acute lung injury associated with docetaxel and bevacizumab. Clin Oncol (R Coll Radiol) 2007; 19: 803-805.

7. Ochoa R, Bejarano PA, Glück S, Montero AJ. Pneumonitis and pulmonary fibrosis in a patient receiving adjuvant docetaxel and cyclophosphamide for stage 3 breast cancer: a case report and literature review. J Med Case Rep 2012; 6: 413. doi: 10.1186/1752-1947-6-413.

8. Gurram M.K, Pulivarthi S, McGary CT. Fatal hypersensitivity pneumonitis associated with docetaxel. Tumori 2013; 99: 100-103. doi: 10.1700/1334.14814.

9. Tamiya A, Naito T, Miura S et.al. Interstitial lung disease associated with docetaxel in patients with advanced non-small cell lung cancer. Anticancer Res 2012; 32: 1103-1106.

10. Nagata S, Ueda N, Yoshida Y, Matsuda H, Maehara Y. Severe interstitial pneumonitis associated with the administration of taxanes. J Infect Chemother 2010; 16: 340-344. doi: 10.1007/ s10156-010-0058-4.

11. Wang GS, Yang KY, Perng RP. Life-threatening hypersensitivity pneumonitis induced by docetaxel (taxotere). BJC 2001; 85:1247-1250.

12. Grande C, Villanueva MJ, Huidobro G, Casal J. Docetaxel-induced interstitial pneumonitis following non-small-cell lung cancer treatment. Clin Transl Oncol 2007; 9: 578-581. Review.

13. Wiatr E. Polekowa i popromienna choroba śródmiąższowa płuc. In: Wiatr E, Rowińska-Zakrzewska E, Pirożyński M (ed.). Choroby śródmiąższowe płuc. Alfa-medica press 2012: 134149.

14. Rowińska-Zakrzewska E. Rozpoznawanie chorób śródmiąższowych płuc. In: Wiatr E, Rowińska-Zakrzewska E, Pirożyński M (ed.). Choroby śródmiąższowe płuc. Alfa-medica press 2012: 81-85.

15. Karacan O, Eyüboglu F.O, Akcay S, Ozyilkan O. Acute interstitial pneumopathy associated with docetaxel hypersensitivity. Oncology 2004; 27: 563-565. 